Aim To assess the psychometric properties of the Dutch_ASQ-60. Material and Methods Parents of 426 term-born and 1111 preterm-born children from the prospective cohort study Lollipop filled in the Dutch_ASQ-60 and a general questionnaire on educational problems, when the children were 57-63 months old. Dutch cut-off values, reliability and validity (content, construct and concurrent) of the Dutch_ASQ-60 were determined for both the original ASQ score (at least 1 abnormal ASQ Domain-score) and the ASQ-Total score. Furthermore mean domain scores of the Dutch_ASQ-60 were compared with versions in other languages.

Results There were no problems with content validity in an expert meeting. Cronbach's alpha, as measure for reliability was 0.86 for the ASQ-total score. Male gender, prematurity, low paternal education, low family income and small-for-gestational-age (SGA) were associated with abnormal ASQ scores, confirming construct validity. Concurrent validity at age 5 for special educational needs was good for both the original ASQ score (sensitivity $80 \%$ and specificity $78 \%$ ) and the ASQ-Total score (sensitivity $65 \%$ and specificity $94 \%$ ). Area under the curve (AUC) for the ASQ-Total score was 0.86 . Mean ASQ-scores for the Dutch_ASQ-60 differed only slightly from other countries: Cohen's delta was above 0.5 for 3 out of 15 comparisons.

Conclusion The Dutch_ASQ-60 has good psychometric properties to screen for developmental problems at age 5 years.

\section{NUCLEAR TRANSIT SCINTIGRAPHY (NTS) PROVIDES OBJECTIVE ASSESSMENT OF GASTROINTESTINAL TRANSIT IN CHILDREN WITH SLOW-TRANSIT CONSTIPATION (STC)}

doi:10.1136/archdischild-2012-302724.1768

\begin{abstract}
1,2,3Yl Yik, ${ }^{4} \mathrm{DJ}$ Cook, ${ }^{4} \mathrm{DM}$ Veysey, ${ }^{4} \mathrm{CF}$ Tudball, ${ }^{4} \mathrm{BS}$ King, ${ }^{4} \mathrm{KA}$ Morris, ${ }^{4} \mathrm{TM}$ Cain, 2,3,5JM Hutson, ${ }^{3} \mathrm{BR}$ Southwell. 'Department of General Surgery, Faculty of Medicine, University of Malaya, Kuala Lumpur, Malaysia; ${ }^{2}$ Department of Paediatrics, University of Melbourne; ${ }^{3} G u t$ Motility and Research Laboratory, Murdoch Children's Research Institute; ${ }^{4}$ Department of Biomedical Imaging; ${ }^{5}$ Department of Urology, Royal Childrens Hospital Melbourne, Melbourne, VIC, Australia
\end{abstract}

Background /aims: Children with slow-transit constipation (STC) are resistant to medical treatment. We used a new treatment transcutaneous electrical stimulation (TES) to treat STC children since 2005, with improved symptoms in most children. Homebased TES was available in 2008. We aimed to assess gastrointestinal transit (GIT) in STC children after medical treatment and homebased TES, with nuclear transit scintigraphy (NTS) as an objective assessment. We hypothesized that TES may alter gastrointestinal transit but not medical treatment in STC children.

Methods All STC children were diagnosed by NTS. STC children treated medically ("Control", $\mathrm{n}=29$ - from NTS database) were compared with 45 STC children treated with home-based TES (1-hour dailyx6 months from 2009-2011). Gastrointestinal transit measured gastric emptying $\left(t^{1} / 2\right)$ and colonic transit by geometric centre (GC) at $6,24,30 \& 48$ hours. The effects of treatments were measured by a repeat NTS. Pre- and post-treatment NTS data were analysed with paired t-test; $\mathrm{p}<0.05$ considered significant. Symptoms assessments were based on bowel diary recorded. Ethics approval obtained (HREC30059A\&30116A).

Results Control group has no improvement in symptoms with most STC children treated with home-based TES has improved symptoms. GC and GIT significantly improved in STC children treated with home-based TES (Table 1).

Conclusions We found symptoms and gastrointestinal transit improved in STC children with home-based TES but not with medical treatment. NTS provides objective assessment, which is important to confirm clinical status after treatments and helps to decide on further interventions.

\section{HOME-BASED TRANSCUTANEOUS ELECTRICAL STIMULATION (TES) TO TREAT CHILDREN WITH SLOW- TRANSIT CONSTIPATION (STC): SAFE (SATISFACTION, FEASIBILITY \& EFFICACY) STUDY}

doi:10.1136/archdischild-2012-302724.1769

${ }^{1,2,3} \mathrm{YI}$ Yik, ${ }^{2,3,4} \mathrm{JM}$ Hutson, ${ }^{3} \mathrm{BR}$ Southwell. 'Department of General Surgery, Faculty of Medicine, University of Malaya, Kuala Lumpur, Malaysia; '2Department of Paediatrics, University of Melbourne; ${ }^{3}$ Gut Motility and Research Laboratory, Murdoch Children's Research Institute; " ${ }^{4}$ epartment of Urology, Royal Childrens Hospital Melbourne, Melbourne, VIC, Australia

Background /aims: Home-based transcutaneous electrical stimulation (TES) is a novel therapy for children with slow-transit constipation (STC). TES has evolved from a clinic-based to home-based therapy. We aimed to assess the end-users' responses and views to TES.

Methods TES was self-administered via adhesive electrodes on the abdomen and back (quadripolar stimulation), $60 \mathrm{mins} /$ day for 6 months. Forty STC children/families were assessed by questionnaires (Ethics 30116A) for: rating of the treatment; time consumption; daily routine disruption; feasibility of delivery; symptom improvement, laxatives used; willingness to recommend TES to others and their views on the current device.

Results Thirty-six/40 STC children/families responded (20 males, ages: 3-18 yrs, mean:9 yrs). Symptom improvement developed in $69 \%$ (17\% in < 3 months, 33\% 3-6 months and 19\% >6 months). Forty-seven percent of children reduced laxative use with $19 \%$ unchanged and $33 \%$ unsure about the effect. Seventy-five percent rated the treatment good, while $17 \%$ were unsure about this new treatment. Ninety-seven percent would recommend TES to other children with chronic constipation and $67 \%$ would purchase a machine for booster treatment if required. All families found the instructions of home TES clear and useful. Problems with use included pad adhesiveness (61\%), wire connections (11\%) or both (11\%). All felt home TES was safe and most had minor disruptions to family routines (parents $6 \%$ vs child $28 \%$ ).

Conclusions This study confirms that home-based TES was safe and well accepted by STC children/families with symptom improvement in $2 / 3$ of these children. There were difficulties with existing device that may be overcome by training.

Abstract 1768 Table 1

\begin{tabular}{|c|c|c|c|c|c|c|}
\hline \multirow[t]{2}{*}{ Parameters } & \multicolumn{3}{|c|}{ Control (Medical; n=29, 15 female; age 3-17yrs; mean 8.7yrs) } & \multicolumn{3}{|c|}{ Home-based TES ( $n=45,22$ female; age 3-16yrs; mean 7.6yrs) } \\
\hline & Pre $($ mean $\pm S D)$ & Post (mean \pm SD) & p-value & Pre $($ mean $\pm S D)$ & Post (mean \pm SD) & p-value \\
\hline t $1 / 2$ (mins) & $45 \pm 26$ & $49 \pm 19$ & 0.38 & $42 \pm 18$ & $36 \pm 16$ & 0.06 \\
\hline Geometric centre $6 \mathrm{hr}$ & $1.8 \pm 0.3$ & $1.8 \pm 0.3$ & 0.55 & $1.9 \pm 0.3$ & $1.9 \pm 0.3$ & 0.40 \\
\hline Geometric centre $24 \mathrm{hr}$ & $2.8 \pm 0.4$ & $2.7 \pm 0.6$ & 0.31 & $2.6 \pm 0.4$ & $2.8 \pm 0.5$ & 0.003 \\
\hline Geometric centre 30hr & $3.2 \pm 0.7$ & $3.1 \pm 0.6$ & 0.36 & $2.9 \pm 0.6$ & $3.1 \pm 0.5$ & 0.039 \\
\hline Geometric centre $48 \mathrm{hr}$ & $3.8 \pm 0.8$ & $3.5 \pm 0.7$ & 0.06 & $3.4 \pm 0.7$ & $3.8 \pm 0.7$ & 0.001 \\
\hline Gastrointestinal transit index & $11.5 \pm 1.9$ & $11.0 \pm 1.7$ & 0.18 & $10.8 \pm 1.6$ & $11.6 \pm 1.6$ & 0.002 \\
\hline
\end{tabular}



OF UNCERTAINTY AMONG GP TRAINEES

doi:10.1136/archdischild-2012-302724.1770

${ }^{1} \mathrm{~A}$ Loftus, 'L Keaveney, ${ }^{2} \mathrm{M}$ O'Neill. ${ }^{1}$ Western Training Programme in General Practice, Galway; ' ${ }^{2}$ epartment of Paediatrics, Mayo General Hospital, Castlebar, Ireland

Background and Aims Uncertainty is at the heart of clinical practice. The learning curve leading from apprentice to expert brings us into contact with uncertainty on a daily basis yet there is relatively little emphasis on it in medical training.

This project aimed to explore GP trainees' experience of uncertainty, its impact, and the skills required to counter it.

Methods An eight question survey was distributed to trainees on the Western Training Programme in General Practice exploring their decisiveness, their experience of uncertainty, and the resources they employed to deal with it. Results were analysed with Excel.

Results 45 questionnaires were returned (78\% response rate).

In terms of combating uncertainty, experience and knowledge of "red flags" ranked highest. Clinical knowledge and experience had the biggest impact on decision making, with fear of making a mistake more pronounced among trainees reporting higher degrees of uncertainty $(94 \%$ said it inflluenced their decisions compared to $58 \%$ of the occasionally uncertain). Patients' anxieties and expectations impacted to a lesser extent (74\%).

Conclusion How often trainees experience uncertainty may lessen with advancing clinical knowledge and experience. Support from senior colleagues is important, as is fear of making mistakes. Building personal resilience (emotional support, good lifestyle), and developing self-awareness didn't rank as highly in terms of what trainees found helpful in dealing with uncertainty; perhaps a reflection of a lack of emphasis on these in general in medical training and something that could be explored as a basis for student education in coping with uncertainty.

\section{USE OF OXIMETER IN CLINICAL ASSESSMENT OF INFANTS AT BIRTH IN LOW RISK DELIVERIES AFTER HOME BIRTH IN THE NETHERLANDS}

doi:10.1136/archdischild-2012-302724.1771

${ }^{1} \mathrm{M}$ Smit, ${ }^{2} \mathrm{~A}$ te Pas, ${ }^{3} \mathrm{~J}$ Dawson, ${ }^{2} \mathrm{~A}$ Ganzeboom. ${ }^{1}$ Obstetrics \& Gynecology; ${ }^{2}$ Neonatology, Leiden University Medical Center, Leiden, The Netherlands; ${ }^{3}$ Neonatology Research, The Royal Women's Hospital, Melbourne, VIC, Australia

Background Objective assessment of infant's condition at birth by oximeter is now recommended in resuscitation guidelines. However, midwives supervising home birth in primary care still use color and count heart rate for evaluation.

Aim To evaluate the additional value of an oximeter when assessing term infants after birth in a home birth setting.

Methods During ten months 27 midwives supervising (home) births used a Masimo oximeter directly after birth for ten consecutive minutes. Data were obtained concerning outcomes, interventions, usefulness, applicability and decision-making.

Results During the study period the oximeter was used in 153 uncomplicated births in primary care. Only one infant received supplemental oxygen and one infant received bag and mask, which was the only hospital referral after birth.

The majority of midwives (88\%) found the oximeter easy to use, but in their clinical judgment was not influenced by the use of the oximeter (in $97 \%$ of births). In 5 cases (3\%), the midwife felt uncertain about the infant's condition and the oximeter gave reassurance in all cases and it was decided not to refer.

Forty percent of midwives indicated to use the monitor again if they had one available and in case of suboptimal neonatal condition, all midwives would use it.
Conclusions It is feasible to use an oximeter during low-risk deliveries at home or in hospital, but was not considered an important contribution for evaluation in majority of the cases. However, midwives would prefer the availability of this device in case of suboptimal neonatal condition.

\section{ALKALINE PHOSPHATASE ACTIVITY IN HUMAN COLOSTRUMS AS A VALUABLE PREDICTIVE BIOMARKER FOR LACTATING MASTITIS IN NURSING MOTHERS}

doi:10.1136/archdischild-2012-302724.1772

${ }^{1} \mathrm{~L}$ Bjelakovic, ${ }^{2} \mathrm{G}$ Kocic, ${ }^{3 B}$ Bjelakovic, ${ }^{4} \mathrm{~N}$ Zivkovic, ${ }^{5} \mathrm{D}$ Stojanovic, ${ }^{2} \mathrm{D}$ Sokolovic. ${ }^{1}$ Department of Hygiene, Faculty of Sport and Physical Education, University of Nis; ${ }^{2}$ Institute of Biochemistry, Medical Faculty, University of Nis; ${ }^{3}$ Cardiology, Clinic of Pediatrics, Clinical Center; ${ }^{4}$ Institute of Pathology; ${ }^{5}$ nstitute of Hygiene, Medical Faculty, University of Nis, Nis, Serbia

Mastitis is defined as an inflammation of the mammary gland. It often presents with the disease already at an advanced stage when the treatment is less effective and the health consequences for nursing mothers and their newborn babies are more severe.

From the pediatric viewpoint it is extremely important to predict occurrence of lactating mastitis as early as possible in order to prevent vertical transmission of infections from mother to infant as well as to prevent stopping of newborn breast feeding.

Biochemical investigations have shown that indigenous milk enzyme such as alkaline phosphatase (ALP) which is detectable in the cuboidal (epithelial) mammary gland cells, plays a very important diagnostic role in clinical medicine, since its activity varies in different tissues and serves as a specific indicator of diseased states.

The purpose of this study was to evaluate ALP activity in human colostrum as a possible early predictive biomarker for lactating mastitis in nursing mothers.

During a period from May to July 2010, a total of 60 healthy nursing mothers were prospectively followed from day 1 postpartum to the end of their lactation.

There was a significant difference in colostrum ALP activity $(p<0.001)$ from the breast with mastitis when compared with both the contralateral asymptomatic breast and "healthy" breasts.

In our opinion, determining ALP activity in colostrums could be a valuable biochemical marker for an early prediction of mastitis in nursing mothers.

\section{CHEST DRAIN INSERTION AND TRAINING OF NEONATAL DOCTORS: USE OF AN ANIMAL MODEL}

doi:10.1136/archdischild-2012-302724.1773

'S Garg, 'C Buckely, ${ }^{2} Z$ Sharp, 'S Byrne. 'Neonatal Medicine, South Tees Hospitals NHS Foundation Trust, Middlesbrough, UK; ${ }^{2}$ Cook Medical, Cook Europe Shared Service Centre, Limerick, Ireland

Background and Aims Neonatal pneumothorax is a potentially fatal condition if not managed promptly and effectively. The little training in chest drain insertion is highlighted by doctors regularly. This is compounded by various factors including decreased incidence of pneumothorax and decreased working hours.

The animal models have been used for such training. We started and tested such training model in our unit to improve the skills and confidence of junior doctors in chest drain insertion.

Methods The workshop included presentation (theoretical), videos of procedure and then the hands on experience on dead rabbits. The rabbits were prepared by the local butchers and were easily available. The training was delivered ( 2 hour) as part of regular departmental teaching programme and was conducted in the first few weeks of start of job. A three point likert scale was used to record the feedback. 